\title{
Populismo: entre la razón, la pasión y la lógica de Port-Royal
}

\section{William Brinkman-Clark*}

\section{RESUMEN}

La mayoría de las críticas al discurso populista, especialmente las desplegadas en el ámbito político-electoral, tienden a reducirlo a una apelación o instrumentalización de los afectos y las pasiones. Así, el populismo normalmente se entiende como un contrapunto al discurso liberal ilustrado y, por extensión, un ataque a las democracias liberales que se construyeron sobre él. En este artículo, sustento que más allá de una dicotomía simple entre un discurso sostenido en la razón y otro que lo enfrenta, apelando a lo irracional, el discurso populista es la puesta en práctica, en el ámbito de lo público, de un diferente tipo de razón -cuyo garante de certeza se ubica en el individuo y no en el consenso-, misma que ha resultado mucho más eficiente en el terreno de lo político que su contraparte ilustrada.

\section{PALABRAS CLAVE}

populismo, lógica, Port-Royal, razón, liberal, discurso

* William Brinkman-Clark (Ph.D. en Arquitectura, Universidad Nacional Autónoma de México) es Profesor de Arquitectura de la Universidad Nacional Autónoma de México.

Correo electrónico: wbc@cod2s.com 


\begin{abstract}
The vast majority of critiques to the populist discourse - especially those uttered in the context of political elections - tend to reduce it to either an appeal to or instrumentalization of affects and passions. Thus, populism is usually understood as the opposite of the liberal enlightened discourse and, therefore, as an ataque to liberal democracies constructed thereupon. In this paper, it is my contention that, beyond the simple dichotomy between a discourse based on reason and another that confronts it, appealing to the irrational, the populist discourse is the practical purchase, in the public realm, of another type of reason - which ultimate certainty foundation lies not in consensus but in the individual - which has proven to be more efficient in the political terrain than its enlightened counterpart.
\end{abstract}

\title{
KEYWORDS
}

populism, logic, Port-Royal, reason, liberal, discourse 
...la amenaza del populismo no puede seguir siendo pensada como malversación de la democracia, pues la democracia misma está ya siempre amenazada por sus propias formulaciones inmunitarias. Se trata de ir más allá de esta paradoja.

Sergio Villalobos-Ruminott

Prender la televisión o la radio para ver u oír a la comentocracia local
hablar sobre el populismo ${ }^{1}$ es toda la evidencia necesaria para asegurar que, en efecto, vivimos inmersos en una crisis, en el sentido más estricto de la palabra: un tiempo de quiebre, de ruptura. Parafraseando a Jacques Lezra: el populismo nos acecha; hay una cualidad en él que parece empujarlo a inmiscuirse hasta en la vida de quienes normalmente no pondrían atención al tema político. Ante este avasallador éxito del populismo, asombra ver cómo el ancien régime de la Razón no está dispuesto a aceptar ni la complejidad y consistencia de la teoría que sustenta el discurso populista, ${ }^{2}$

\footnotetext{
${ }^{1}$ Hay una larga lista de teóricos que se ha dedicado a construir la teoría del populismo, y aun más extensa es la de quienes lo han estudiado para describirlo o someterlo a crítica. Destacan intelectuales como Margaret Canovan, Laclau y Chantal Mouffe, y pensadores cuyo trabajo sirvió como punto de partida para la teoría populista, como Schmitt, Canetti y Gramsci, por mencionar algunos. Tratar de abordar esta genealogía en su extensión sería tema para un artículo aparte, por lo que, para avanzar, simplemente me basaré en la definición de populismo de José Luis Villacañas (2015) y en el recuento histórico que de sus manifestaciones en Latinoamérica hace S. Villalobos-Ruminott (2018). Para Villacañas, el populismo, en tanto fenómeno socio-político general, posee ciertas características que parecen estar presentes en todas sus iteraciones históricas - la primera de las cuales sería, probablemente, el peronismo-. La similitud entre las variadas expresiones del populismo muy probablemente se da porque, a pesar de lo que pensarían sus detractores, todas se han apoyado en una fundamentación teórica coherente y consistente, que además es abierta y transparente: el populismo no tiene una agenda maquiavélica oculta, más bien, como dice el refrán popular, es auténtica porque dice lo que piensa.

${ }^{2}$ Como bien lo ha expuesto Villacañas (2015), el populismo es un fenómeno complejo, sustentado en una teoría político-histórica consistente, elaborada por intelectuales virtuosi; menospreciarlo académica o intelectualmente es un error. Quizá uno de los puntos más fuertes del discurso populista es justo aquel que lleva a muchos intelectuales a subestimarlo: la facilidad con que las masas se relacionan con sus productos. Salvo notables excepciones, la academia y la inteligentsia tienen un largo historial de ningunear lo popular como algo simplón que no requeriría o merecería su atención.
} 
ni el hecho de que su éxito se construye a costa del fracaso estructural de las democracias liberales modernas. Más bien pareciera que, para ellos, el populismo es una suerte de deus ex machina que ha venido a resolver el drama civilizatorio de Occidente con un vuelco de la dicha a la desdicha, y el que el héroe moderno esté destinado a sufrir el yerro trágico es debido a la Razón misma. Así, la inteligentsia occidental sufre y trata de evitar el naufragio de nuestras democracias al apelar a la Razón misma, como si ésta fuera el único baluarte capaz de resistir y someter al tumulto populista.

En las primeras páginas de Populismo, José Luis Villacañas hace énfasis en una característica particular a la estructura del populismo, presente en todas sus iteraciones históricas: su anti-institucionalismo. 'Vivimos tiempos de confusión' — dice el autor- 'El fenómeno que la delata es la pérdida generalizada de confianza' (2015: 13). No es demasiado atrevido pensar que existe una relación entre la pérdida de confianza y el anti-institucionalismo; al final del día, fue el concepto mismo de institución y sus materializaciones los que sirvieron, en gran medida, de garante del proyecto moderno (hasta que estas se agotaron). Así como todas las versiones del populismo parecen compartir el anti-institucionalismo como elemento estructural, la gran mayoría de las instituciones modernas mantienen una creencia - entusiasta a un nivel de fanatismo- en la Razón. La vehemencia con que los antipopulistas denuncian la 'irracionalidad' del discurso populista no es más que un síntoma claro de este fanatismo. ${ }^{3}$

El discurso populista agradece el gesto delirante de su oponente. La convicción fundamental del populismo es que el lazo social transita por lo

\footnotetext{
3 Hay algo de verdad en decir que el populismo 'es una ideología contraria a la idea ilustrada de modernidad, a su idea de sujeto racional y su mirada ampliada sobre el mundo' (Villacañas, 2015, 45) pero, como bien indica el autor, no lo hace buscando a un ciudadano simple y poco reflexivo para oponerlo al ciudadano clásico, porque en la época de las masas ese ciudadano clásico es una pequeñísima minoría (quizá en el mismo porcentaje que en la Ilustración, pero ahora, en tiempos de masas, la democratización del todo hace esta ratio más evidente, y el ciudadano clásico se vuelve una clase aún más elite.) El ciudadano experto de la condición posmoderna es ejemplo claro de esto: sistemáticamente renunció a la ciudadanía clásica al asumirse experto en su ámbito particular y delegar la responsabilidad de la cosa pública a otro - históricamente, al experto en política en un primer momento, y al económico-administrativo después- porque nadie, más que el experto en la cosa pública tiene tiempo para la cosa pública (Brinkman-Clark, 2015).
} 
afectivo, e 'impugna que la base de la sociedad sea racional' (Villacañas, 2015: 15-16). Que su adversario siga añorando un ciudadano clásico que nunca existió, que conformaba pueblos menos pasionales — pero más imaginarios_, en tiempos más racionales — pero menos reales-, es una estrategia que fortalece las consignas sobre las cuales se construye el discurso del populismo. Acrecienta la percepción generalizada, en Occidente, de que somos nosotros: el pueblo, contra ellos: la élite. La teoría populista identificó y supo aprovecharse del delirio liberal sobre el contrato social. ${ }^{4}$ En palabras de Villacañas:

El populismo es la teoría política que siempre ha sabido que la razón es un bien escaso e improbable. En la política de la época de las masas, la razón es la última de las potencias masivas capaces de responder a la crisis. En todo caso, es una función bastante limitada en su capacidad de producir vínculos sociales. (2015: 14-15)

\begin{abstract}
Al tratar de dar cuenta del trágico derrumbe del orden liberal, sus defensores evitan asumir una posición crítica y recurren -irónicamente- a una jugada del manual de su contrincante: la fabricación de un enemigo. Según sus detractores, el populismo avanza por culpa del entusiasmo de la gente ${ }^{5}$
\end{abstract}

\footnotetext{
4 Estos pasajes no deben entenderse como una crítica a las democracias liberales y al liberalismo como un todo. Simplemente, en tanto hegemonía, históricamente se mostraron incapaces de reconocer sus limitaciones prácticas y epistemológicas. En una frase que anticipa el tratamiento con que Laclau —de la mano de Freud, Lacan y Schmitt- problematizó la cosa pública, Villacañas nota: 'Unir inteligencias en una razón común es algo milagroso. En realidad, sólo puede hacerse mediante instituciones fuertes y comprometidas [...] sin embargo, la razón y la inteligencia exceden a la ciencia, sobrepasan el arco de las instituciones representativas y se configuran en lo que durante un tiempo se llamó filosofía.' (2015: 15). Identificar y problematizar la naturaleza del vínculo social es un tema por demás importante para cualquier filosofía política, y si bien la manera en que lo hicieron las democracias liberales fue eficiente y coherente por un tiempo, el populismo supo expresar la problemática de la realidad contemporánea de una manera más coherente, y, por tanto, más eficiente. En especial, habría que someter a una fuerte crítica la naturaleza juristocrática que inevitablemente fue constitutiva a toda democracia liberal moderna (Villalobos-Ruminott, 2018).

5 En realidad, en tanto categoría, el entusiasmo era problemático desde la Ilustración. Kant le dedica varias entradas en su Antropología (2014), y debe considerarse con detenimiento el vínculo indisoluble que existe entre el entusiasmo y la figura del líder, por ejemplo, el mariscal. Si bien la modernidad decidió ignorar estas advertencias de Kant, e irse por la 'vía de la primera crítica', es imperativo recuperar la intuición kantiana que lo condujo a escribir tanto la tercera crítica como su Antropología. Recientemente, José Luis Barrios (2018) hizo una excelente lectura del gesto 'populista' que significó entregar la residencia presidencial de México al pueblo, haciendo hincapié no sólo en el entusiasmo que generó, sino en cómo éste puede ser instrumentalizado y participar en el devenir de la ideología y el papel que López Obrador, en tanto mariscal, juega en todo este despliegue de lo sensible.
} 
el discurso populista seduce al lado pasional, afecta. Insisten: la culpa de todo la tiene esa irracionalidad de la mayoría, que ahora pone en riesgo el intachable proyecto liberal. ${ }^{6}$ El campo de batalla, por lo menos para ellos, parece estar dispuesto: Razón contra Pasión. Así, por más que el barco se hunda, liberales y conservadores creen con seguridad que la posteridad los juzgará y quedarán del lado correcto de la historia. No es casualidad que invoquen tanto a Churchill.

Pero, ¿en realidad es todo tan simple? ¿Hubiera bastado con que la modernidad hubiera sacado a todo el pueblo de su minoría de edad para evitar el fiasco populista? ¿Tendríamos que hacer caso a Steven Pinker (2018) y tenerle paciencia a la modernidad? O, más bien, ¿no serán todas estas preguntas falsas? Los sectarios de la Ilustración se muestran ciegos al proceso mismo de ilustración: el populismo no propone un discurso que se opone a la Razón mediante el recurso afectivo, propone otro tipo de razón. Los ilustrados son incapaces de cuestionar los axiomas que sustentan todo su sistema, no ponen en duda su concepto particular de razón, aquel que sólo existe como antítesis de la pasión (al pathos como heteronomía).

Lo que me interesa aquí no es esta oposición, tan presente y evidente en la discusión pública, entre un ancien régime racional y un populismo pasional y afectivo; sino justamente cómo este recurso, tan usado por liberales y conservadores, desvela una historia más profunda: esa que entiende a la razón no como un valor universal, sino como una herramienta de dominio. No es difícil ver que el populismo se inscribe perfectamente dentro de una historia de la razón, si ésta la entendemos dentro del marco de una dialéctica de la ilustración. Habría que pensar que el populismo, antes que cualquier otra cosa, apela a un entendimiento distinto de la razón;

6 Quiero insistir en el carácter sintomático de estos argumentos, y lo que claramente revelan. ¿Qué no, al quejarse de la sublevación de esta mayoría irracional que pone en riesgo a las democracias, se muestra que, en verdad, lo que vivimos todo este tiempo eran oligarquías y aristocracias disfrazadas de democracias? Especialmente si nos atenemos a los axiomas que definen, históricamente, el surgimiento y la razón de ser de las democracias modernas, tal y como lo expone Luigi Ferrajoli (1999). 
y que la instrumentalización de dicha conceptuación —que no transita por lo que la razón es, sino por cómo funciona - se ha mostrado brutalmente eficiente en la época de las masas y los medios masivos de comunicación. ${ }^{7}$

II.

La experiencia debe ser nuestro único indicador de caminos.

La razón puede hacer que nos extraviemos.

John Dickinson, Convención constitucional de 1787

La idea de que existen diferentes maneras de entender la razón, o lo que es la racionalidad, es algo que la filosofía nunca ha dejado de problematizar, en especial a partir de la segunda mitad del siglo XX. También queda claro que es una problematización que no llega al discurso político, por obvias razones. Antes de abordar estas discusiones y su relevancia en el discurso populista actual, creo importante regresar al momento histórico en que primero se arguyó y se fundó el concepto de razón, tal y como se entiende hoy en día.

A lo largo de los siglos XVII y XVIII, las discusiones que pretendían entender y dar forma a la noción de la racionalidad humana tenían como

\footnotetext{
7 Una característica de la teoría populista, quizá de las más importantes si queremos explicar su reciente éxito, es que se trata de una teoría elaborada en y para el contexto de nuestros tiempos; esto es, reconoce que estamos en la época de los medios masivos de comunicación y sabe explotarlos mejor que ninguna. El populismo se sabe una construcción retórica, el uso de los medios le es consustancial. En dicha construcción encontramos algunas otras características constantes de los populismos. Villacañas (2015) enfatiza que la teoría populista argumenta, axiomáticamente, que el lazo social no tiene una naturaleza racional sino afectiva. No cabe duda que hay una relación intrínseca entre una teoría que entiende las limitaciones empíricas y epistemológicas de las sociedades modernas y comprende, mejor que nadie, la naturaleza de las masas y la técnica moderna por excelencia: el medio masivo de comunicación -especialmente los más recientes, coincidentes con el neoliberalismo de segundo orden (Villalobos-Ruminott, 2013 y 2018), como Twitter, Facebook e Instagram. Es una relación simbiótica que ha sabido producir el mejor discurso para los medios contemporáneos, y por ello, el más eficiente. Gracias a esta relación, la teoría populista ha producido discursos retóricos que, aunque diferentes en sus distintas iteraciones históricas, guardan todos una estructura similar: entienden la realidad en términos intensivos y no extensivos, definen al pueblo de acuerdo a ello, y comprenden que, en la época de las masas, la materialización de este discurso es más eficiente entre más sencillas sean sus categorías. De ahí que todo discurso populista parece compartir dos categorías esenciales: la dicotomía amigo-enemigo y la figura del líder.
} 
fin configurar un dispositivo que ayude a las culturas europeas a construir certeza, en una época de incertidumbre general. ${ }^{8}$ De esta gran discusión, el tipo de razón que emergió triunfante es la que comúnmente se conoce como razón ilustrada. En la Europa de los siglos XVII y XVIII, esta propuesta de racionalidad, de la cual Kant es probablemente el más célebre proponente, expresó de manera casi perfecta las necesidades y el espíritu de quienes la formularon. Una razón autónoma, crítica, secular y consciente de sus propios límites se constituyó como la herramienta perfecta para que una pequeña burguesía, liberal e ilustrada, se consolide en el poder. Si bien una importante propuesta de la razón ilustrada era la emancipación del hombre, el sapere aude nunca superó su propia naturaleza instrumental, y terminó por ser la herramienta de dominio por excelencia de las élites liberales (Adorno y Horkheimer, 1994).

Pero la razón ilustrada no fue la única propuesta. No se descubrió, como si fuera un regalo divino o parte constitutiva de la naturaleza humana; al igual que el discurso populista, la razón ilustrada fue una construcción de y para su época. ${ }^{9}$ A la pregunta de cómo terminar con la incertidumbre se adelantaron varios proyectos. El que más me interesa aquí, dada la similitud estructural que guarda con ciertos fundamentos del discurso populista, es la Lógica de Port-Royal. Publicada en 1662, La Lógica o el arte de pensar, comúnmente conocida como Lógica de Port-Royal, fue un manual de lógica de Antoine Arnauld y Pierre Nicole, miembros del movimiento jansenista, de fuerte influencia cartesiana. Al proponer, desde las primeras líneas del

\footnotetext{
8 De ninguna manera pretendo que ésta fuera la única causa detrás de la discusión en torno a la razón, pero sin duda es de las más importantes. Diversos autores que han hecho revisiones históricas sobre la época, como Adorno y Horkheimer (1994), Blumenberg (2011), Foucault (2010) y Kuhn (2004), entre otros, parecen coincidir — cada uno a su manera y desde aproximaciones teóricas distintas - tanto en la incertidumbre epistemológica que se abre, como en la manera en que un tipo de racionalidad emerge para tratar de socavar la duda. También cabe mencionar que, por un largo tiempo — por lo menos hasta 1991esta racionalidad fue brutalmente eficiente en su tarea.

9 En palabras de Villacañas, al hablar de populismo hay que pensar siempre en 'el carácter construido del populismo, en su novedad, en su dinamismo, en sus estrategias de construcción de amistad, en su carácter flexible de respuesta a retos del presente' $(2015,27)$. Más adelante añadirá que 'Si definimos el populismo como una construcción, ésta tiene un material muy concreto: lenguaje' (2015: 45).
} 
texto, que 'nada hay más estimable que el buen sentido y la justedad del espíritu para discernir lo verdadero de lo falso' (1987: 17) manifestaron su búsqueda de certeza. El interés primordial de la obra, según los autores, era la formación del juicio, esto es: que el discernimiento de la verdad fuera lo más exacto posible.

La Lógica de Port Royal fue una pieza fundamental en la construcción de todo el edificio del saber ilustrado (Foucault, 2010), y no cabe duda que muchos tratados de lógica, así como los de propedéutica y epistemología de la época, estuvieron de alguna manera en discusión con ella. La parte central de la Lógica de Port-Royal se centra en la elaboración de juicios, en tanto que éstos afirman que una cosa concebida es tal o no es tal (Marin, 2006; Arnauld y Nicole, 1987). Esta afirmación sobre lo que es el juicio fue compartida, en adelante, por todo el proyecto ilustrado. Tanto para Port-Royal como para la Ilustración, reducir la incertidumbre era la tarea a seguir: poder saber que lo que afirmamos que es, en efecto, sea; para lograr este cometido, no había herramienta más útil que la lógica (1987: 15, 17-18).

En lo que refiere al discurso populista, no importa tanto lo que la Lógica de Port-Royal comparte con la gran construcción racional de Occidente, sino aquello que, en su momento, fue un punto irreconciliable para la época: el referente de certeza de la lógica; aquello que da validez a mi juicio y comprueba que cuando digo que algo es, estoy en lo correcto y en efecto, es eso. En el caso de Port-Royal, el axioma, o la petición de principio fundante, que daría sustento a todo juicio sería un non sequitur para la razón ilustrada: la idea clara y distinta. 


\begin{abstract}
III.
Confía plenamente en el Señor, y no te fíes de tu inteligencia. Cuenta con él en todos tus caminos, y él dirigirá tus senderos.
\end{abstract}

Proverbios 3:5

Los proyectos ilustrados de Kant y de Hume, así como la mayoría de las obras que acompañan el canon de esta época, buscaban, al igual que la Lógica de Port-Royal, encontrar la manera de reducir la incertidumbre. Difieren, sin embargo, en la causa de esta incertidumbre y, por lo tanto, aunque la finalidad de ambos proyectos fuera la misma, y también en el medio para solventarla: la diferencia en sus fundamentos hizo que las propuestas fueran radicalmente opuestas. Para Kant y Hume, sólo pertenecía a la razón aquello que se puede explicar y ofrecer a los demás con pruebas; entonces, lo que debía construirse era todo un sistema cuyas reglas me permitieran salir de mí mismo y de mis certezas (prejuicios), para construir juicios que se sostengan ante el escrutinio de los demás. En otras palabras: todos debemos seguir el mismo set de reglas al razonar, porque sólo así sabremos que lo que construimos y creemos cierto es, en efecto, cierto.

A diferencia de este proyecto, para Port-Royal razonar es algo que llevamos a cabo de manera natural, no serviría describir ni explicar las reglas de este proceso porque, como es natural, simplemente es algo que haces ( $\mathrm{y}$ si no lo haces, entonces no sirve de nada enseñarte algo que por naturaleza no 'tienes'). Para la Lógica de Port-Royal no hay que construir ningún set de reglas para razonar, sino para depurar: la historia del hombre era según los portroyalianos, hasta ese momento, una historia de la confusión en la que se usaba una palabra para describir varias cosas o varias palabras para describir una cosa. Su tarea era formular una lógica que resolviera eso. Cualquier persona que tenga un mínimo grado de familiaridad con la 
estructura del discurso populista podrá empezar a intuir un cierto grado de similitud con la propuesta de Port-Royal.

Si la utilidad de una lógica es reducir la confusión mediante una depuración, habría que preguntarse, ¿qué hay ahí, debajo de aquello que debo depurar? Para Port-Royal, debajo de lo confuso están siempre las ideas claras y distintas. ${ }^{10}$ Según Port-Royal, las ideas son aquello que poseemos y nos permiten adquirir conocimiento sobre el mundo: en una abierta oposición a la postura empirista, la Lógica de Port-Royal niega que las ideas procedan de los sentidos: usando como ejemplo el cogito cartesiano, proponen que en todo ser humano existen ideas anteriores a toda experiencia, y que sólo conocemos el mundo gracias a que poseemos, naturalmente, estas ideas (Arnauld y Nicole, 1987: 56-64). La verdadera certeza sobre lo que el mundo es la tiene cada hombre dentro de sí. No haría falta acudir a los demás para que verifiquen y censuren mi juicio, porque, en palabras de Louis Marin, según los portroyalianos:

no podemos tener ningún conocimiento de lo que está fuera de nosotros más que por la mediación de las ideas que están en nosotros. Pero, a la vez, es necesario que la representación acceda a la cosa misma, que la idea en nosotros sea la cosa fuera de nosotros y, como ella no puede serlo del todo, puesto que ella es cosa mental, hace falta que ella reciba el estatuto jurídico de la cosa, estatuto que se llama verdad. (2006: 366)

El hombre nace, o es creado, con ciertas ideas claras y distintas. La verdad que señala Louis Marin no puede ser otra cosa que el orden divino y la bondad cartesiana de Dios. Si el hombre hubiera usado estas ideas de manera correcta y adecuada, todos sus juicios serían necesariamente claros y distintos, pero, a lo largo de la historia, el ser humano se ha dedicado a crear confusión.

\footnotetext{
10 '... una idea nos es clara cuando nos afecta vivamente, aunque no sea distinta [...] toda idea es distinta en tanto que es clara y que la oscuridad sólo proviene de la confusión de la idea' (Arnaud y Nicole,1987: 96).
} 
La capacidad de confusión proviene, básicamente, de los sentidos. En la medida en que éstos son contingentes y, por tanto, arbitrarios (Arnauld y Nicole, 1987: 98) conducen a generar y construir confusión. Un niño aprendería juicios confusos, enseñados por los demás, y los ataría incorrectamente a ideas naturales que no les corresponden. La experiencia y los sentidos llevan al hombre a usar el lenguaje figurado, que abre la puerta a la confusión. Al igual que el idioma analítico de John Wilkins (Borges, 1998), el gran proyecto de Port-Royal era depurar el lenguaje de esta confusión; al hacer un correcto uso de las ideas creían en la posibilidad de reducir todos los juicios a sus formas más simples, y así evitar cualquier instancia de confusión, arbitrariedad, duplicación, metaforización, etcétera. ${ }^{11}$ Como la misma Lógica lo dice:

El único remedio para evitar este inconveniente [la confusión] es el desprendernos de los prejuicios de nuestra infancia y el no creer nada de lo que es competencia de la razón, porque, en otra ocasión así lo hayamos hecho; más bien ha de creerse porque así lo juzgamos en el momento presente. Así, nos limitaremos a nuestras ideas naturales, y en cuanto a las confusas, no retendremos sino lo que poseen de claro (Arnauld y Nicole: 104).

El proyecto de Port-Royal coloca la totalidad de la validez en la naturaleza (divina) del hombre. Cada ser nace con todo lo necesario para conocer el mundo de una manera válida y verdadera. Si el hombre se encuentra en un momento de duda, no debe hacer otra cosa más que limitarse a lo que sus ideas naturales, innatas, le reafirmen del mundo. Según Port-Royal, no necesito del contacto con otros seres humanos para conocer el mundo de manera verdadera; incluso, la modernidad, entre más instituciones crea, no hace otra cosa que complicar lo que, por naturaleza, es simple.

El proyecto portroyalino no parece preocuparse por el solipsismo, como sí lo hace la Ilustración; es más, podría decirse que propone más

11 La Lógica hizo el esfuerzo de exponer la completitud de su proyecto, que por razones de brevedad no retomaremos aquí, pero debe notarse que trataron todo tipo de conocimiento que, para ellos, resultara necesario explicar, como la lógica misma, la moral, la ciencia, las instituciones, etcétera. 
solipsismo: en el yo de cada quien está la verdad. No es un salto demasiado aventurado pensar que para un jansenista, convencido de los postulados de Port-Royal, la mayoría de las instituciones y los otros no son más que una peligrosa fuente de fake news (especialmente si lo que dicen contraviene lo que me manifiesta mi espíritu). De tal manera, un monje enclaustrado en su celda (o un internauta que se autolimita a leer sólo Breitbart o el New Yorker), que conoce el mundo sólo mediante sus ideas, tendría menos posibilidad de errar en sus juicios sobre lo que el mundo realmente es que quien vive una vida cosmopolita. ${ }^{12}$ Para Port-Royal, pareciera que el otro sólo está aquí para confundirnos y llevarnos por la vía del mal, o para reforzar lo que ya sabíamos por naturaleza. No creo muy lejano o atrevido afirmar que el mundo que supone la Lógica de Port Royal está claramente separado entre amigos y enemigos. ${ }^{13}$

\author{
IV. \\ 'Si crees en ti mismo, todo es posible' \\ Miley Cyrus (42.3 millones de seguidores en Twitter)
}

El proyecto ilustrado no puede, a nivel axiomático, aceptar la propuesta de la Lógica de Port-Royal. ${ }^{14} \mathrm{Si}$ bien la intención de ambas es terminar con la incertidumbre, la Ilustración creía que gran parte de la confusión derivaba de la hegemonía del dogma religioso, mientras que Port-Royal entiende

\footnotetext{
12 'Dos son los caminos que nos llevan a creer que una cosa es verdadera. El primero es el conocimiento que alcanzamos por nosotros mismos [...] a esto en general puede denominársele razón [...] El otro camino que nos lleva a creer que algo es verdad es la autoridad de las personas que son dignas de ser creídas [...] llamamos a esto fe o creencia' (Arnauld y Nicole: 466).

13 'Puesto que el populismo construye el pueblo como comunidad, lo construye como totalidad. Pero en la medida en que lo construye mediante una operación hegemónica atravesada por el conflicto tiene que hacerlo mediante la fractura del cuerpo político en amigos y enemigos. El populismo construye la comunidad popular de los amigos. Supone un cuerpo social y político más amplio que fractura en dos: el de los amigos del pueblo y el de los enemigos del pueblo' (Villacañas, 2015: 27).

14 No cabe duda que el proyecto ilustrado y su resultante razón ilustrada son temas tratados a fondo - lo cual debe seguir haciéndose. La escala titánica de su visión hace que cualquier reducción sobre ella parezca irresponsable; sin embargo, hay que hacerla si uno quiere escribir un artículo y no un libro de veinte volúmenes.
} 
— de la mano del cartesianismo- ${ }^{15}$ que la creencia en la bondad de Dios significa que existe una correspondencia entre el mundo y las ideas innatas. El proyecto de la Ilustración finca en el solipsismo gran parte de la culpa por la minoría de edad del hombre; ante esto, busca en el otro el referente que dé validez a su estructura racional. Sólo en la medida en que debo construir una racionalidad con el fin de comunicarme con los otros, con la mayor objetividad posible, puedo reducir la incertidumbre. No sólo hay un primer momento de duda del yo, sino que, además, debo admitir siempre la duda del otro sobre mi certeza; la validez que dé para sustentar mi certeza debe ser elaborada para el otro. ${ }^{16}$

Port-Royal toma la vía directamente opuesta, por lo menos en lo referente a la validez y la certeza. El locus final de la verdad está dentro de cada quien, y la certeza de que mi verdad es objetiva la da la creencia axiomática en la bondad de Dios. El ejercicio hacia la reducción de la incertidumbre transitaría por el pensamiento personal, por una confianza en el yo, en aquello que el yo piensa y sabe, más allá del esfuerzo de sus sentidos y de los otros por confundirlo.

Dados los presupuestos y los alcances de la razón ilustrada, no podía tener otro fin que el de crear sistemas lógicos y epistemológicos que necesariamente requerían ser coherentes y consistentes. Por esto, su sujeto tenía que serlo también, por lo menos teóricamente. En la medida en que la verdad se encuentra en la capacidad de un sujeto de someter sus juicios ante la crítica interminable de los demás, la razón ilustrada creó un sistema

15 'Pero como me pasan unas cosas que advierto con claridad de dónde, a dónde y cuándo se me aparecen, y enlazo su percepción sin interrupción alguna con la vida restante, estoy seguro que las percibo cuando estoy despierto, y no en sueños. Y no debo dudar en lo más mínimo de su verdad, si una vez que he convocado a todos los sentidos, la memoria y el intelecto para examinarlas, ninguno de ellos me manifiesta nada que se oponga a los demás. Del hecho de que Dios no sea engañoso se sigue que yo no me engaño en absoluto en esto. Pero ya que la necesidad de llevar una vida activa no concede siempre una pausa para un examen tan detenido, se ha de confesar que la vida humana está expuesta a frecuentes errores en lo que se refiere a las cosas particulares, y se ha de reconocer la debilidad de nuestra naturaleza' (Descartes, 1995: 153).

16 Horkheimer nota que, para los adalides de la civilización burguesa: 'La razón había de regular nuestras decisiones y nuestras relaciones con los otros hombres y con la naturaleza. Se la concebía como a un ente, como una potencia espiritual que mora en cada hombre. Se declaró que esa potencia era instancia suprema' (2007: 21). 
de generación de conocimiento válido, en extremo complejo. El sujeto de la Ilustración no sólo habrá de ser capaz de elaborar juicios consistentes, sino que debe contraponer estos juicios a todos los demás que ha emitido, y asegurar que son coherentes entre sí.

Al contrario, la Lógica de Port-Royal crea un sistema que, por lo menos en apariencia, es más simple. El sujeto portroyaliano es, por naturaleza, poseedor de la verdad. De lo único que debe ser capaz es de creer en sí mismo, de buscar en su ser esas ideas innatas y con ellas producir juicios. Si el mundo le dice algo, lo único que debe hacer es confiar en sí mismo, ese movimiento le comprobará si lo que el otro le ha propuesto es verdadero o falso. No hace falta construir sino depurar todo lo que, hasta ahora, el mundo ha hecho de manera errada.${ }^{17}$ Esto no debe entenderse como algo irracional, más bien, como un método distinto de razonar, con un set de axiomas por completo distinto a los que eventualmente conformarían la razón ilustrada y el marco liberal que de ella se desprendió, el cual configuró una gran parte de la estructura de nuestras democracias modernas.

La conformación específica de las sociedades en los siglos XVII y XVIII, en especial lo referente a la distribución de las estructuras del podersaber, fue necesaria para que un proyecto como el de la razón ilustrada saliera triunfante. No creo que pueda decirse lo mismo de la época de las masas. Los herederos contemporáneos de la razón ilustrada se lamentan de una sociedad que ha recaído en la minoría de edad, pero, ¿alguna vez salimos de ella? Youtube, Twitter, Facebook y la industria cultural no tuvieron agencia en la creación de una cultura en la cual, entre menos complejo el pensamiento, mejor; esa cultura nunca ha dejado de estar ahí.

El discurso populista no sólo se dio cuenta de esto; también entendió que, a diferencia de la Ilustración, la mayoría ahora detenta un poder que

17 La Lógica de Port-Royal sí considera la construcción del conocimiento, esto se trata en las partes sobre la ciencia y el método. Sin embargo, hay que hacer notar que los axiomas que configuran a las ideas claras y diferentes son los mismos que rigen la ciencia y el método; por desgracia, el espacio no da para abundar en las particularidades con las cuales Port-Royal trata la construcción de conocimiento. 
antes no tenía. ${ }^{18} \mathrm{El}$ populismo entiende que el pensamiento complejo es, pues, complejo. También que, para la condición posmoderna, esa complejidad no aparece como una característica que valide su verdad, esto es: no porque sea complejo, significa que es verdadero. Por último, que - en tiempos de expertos- sólo los expertos en argumentación o en política, a la liberal, tienen tiempo para desarrollar, entender y apreciar la complejidad, consistencia y coherencia del episteme ilustrado-liberal, y por qué tendría valor el tipo de certeza que nos brinda.

Al saber todas estas cosas, el populismo sólo tiene una pregunta más que hacerse: esta maravillosa, compleja y fascinante arquitectura de la razón ilustrada, ¿tiene referente real? ¿tiene algo que ver con la experiencia cotidiana del mundo del ciudadano de una democracia moderna? Sin duda, la respuesta es un contundente no. En el mejor de los mundos posibles, todo ciudadano entendería la importancia de los presupuestos que impulsan al proyecto ilustrado; sabría lo que la presunción de autonomía significa para la construcción política y jurídica de Occidente. Sin embargo, no es así; no queda duda que quienes prometieron lo que ahora no existe y se lamentan de ello son las democracias modernas. El populismo no tuvo la tarea difícil; en realidad, no hizo más que entender y denunciar la enorme distancia entre el mundo que prescriben y describen las democracias modernas, y el mundo que vive el demos. Para hacerlo, no recurrió a la irracionalidad, sino a una noción diferente de razón, muy similar a la descrita por los teóricos de Port-Royal.

\footnotetext{
18 El que este poder se lograra por la vía del pensamiento ilustrado y liberal es, sin duda, una cruel ironía. Como bien lo nota Villacañas, 'Si definimos el populismo como una construcción, ésta tiene un material muy concreto: lenguaje. Por eso es afín a la democracia. Necesita libertad de expresión. Y reclama acceso al campo de lo público' (2015: 45). Habría que añadir que necesita un tipo de libertad de credo: lo que yo crea vale simplemente porque yo lo creo.
} 


\begin{abstract}
V.
'De alguna manera, Donald Trump tiene esta coalición. Los nazis lo quieren y Netanyahu lo quiere. Tiene a los antisemitas y a Sheldon Adelson. Que alguien me explique eso.' Bill Maher
\end{abstract}

A lo largo de las décadas de los setenta y los ochenta, Christopher Cherniak desarrolló su teoría sobre agentes racionales mínimos, publicada en su texto Minimal Rationality (1986). Su propuesta iba directamente en contra del sujeto cognitivo creado por la Ilustración. Éste, según Cherniak, era un modelo de sujeto ideal al cual se le demanda ser un agente racional completo, cuyos juicios sólo son interpretados como racionales si son, por un lado, consistentes en-sí, y por el otro, coherentes con el resto del set de juicios y creencias elaborado por el sujeto. Ante este agente racional ideal, Cherniak propone una alternativa de acuerdo a las limitaciones de la realidad: un agente racional mínimo, que tiene facultades, tiempo y recursos materiales limitados. Dicho agente necesariamente debe incorporar un grado de heurística en su formulación de juicios y, dada la imposibilidad de la tarea, jamás se le demandaría que todos sus juicios sean coherentes entre sí.

Según la propuesta de Cherniak, lo único que se le debe pedir a cualquier agente para decir que es racional es que sea capaz de elaborar juicios a partir de las estructuras del modus ponens y modus tollens. Estos juicios no deben estar de acuerdo con otros anteriores que haya elaborado el agente, ni con el set de creencias que diga tener o no; el título de agente racional sólo tiene que ver con la posibilidad de elaborar este tipo específico de juicios. ${ }^{19}$ Esta línea de pensamiento ha resultado revolucionaria para

19 Si bien la propuesta de Cherniak se elabora desde una perspectiva diferente, su racionalidad mínima tiene mucho en común con la razón subjetiva de Horkheimer, quien la definía como 'la capacidad de clasificación, de conclusión y deducción, sin reparar en qué consiste en cada caso el contenido específico' (2007: 15). 
varios campos en el ámbito de las ciencias sociales, en especial la economía, donde ayudó a comenzar una rama denominada behavioural economics, que ha mostrado ser extremadamente eficiente en sus predicciones: porque ha dejado de presuponer al hombre como un agente racional ideal —el homus economicus - y lo ha ubicado en un contexto sociocultural cuya conformación actúa como limitante en la posibilidad de cualquier decisión racional ideal.

El discurso populista sigue, en la medida de lo adaptable, las premisas de Cherniak, sin embargo, no ha gozado del reconocimiento positivo de su contraparte en el ámbito de la economía. La diferencia reside, quizá, en que, si bien el modelo de racionalidad mínima significó un aumento en la predictibilidad de ciertos cálculos económicos, en el ámbito de la política su instrumentalización no significó ningún beneficio para las estructuras liberales en el poder. Al contrario, evidenció su incapacidad fundamental de adaptación. En lugar de modificar sus axiomas, las democracias modernas simplemente adoptaron las tácticas de sus contrapartes populistas, ${ }^{20} \mathrm{sin}$ entender el relevante rol que juega la flexibilidad argumentativa en la teoría populista, algo que la liberal no podía compartir. En palabras de Villacañas:

El populismo es ante todo una construcción lingüística y asume esta racionalidad propia. En realidad el populismo dispone de una política comunicativa ultramoderna dirigida al afecto, al sentimiento, a la teatralidad y a la espectacularidad [...] Sabe algo: que el lenguaje tiene una gran capacidad de producir efectos sociales, sentimientos, imitaciones [...] Se ha dicho que el populismo promueve formas comunicativas que no privilegian la argumentación racional y analítica [...] Pero no lo hace así porque quiera producir analfabetismo político. Lo hace así porque lo hacen todos. [...] Quiere producir evidencias compartidas y las formas comunicativas

\footnotetext{
20 Tanto así que hablar de un partido o un movimiento político contrario en ideología al populismo es una premisa ingenua, sea de 'derecha' o de 'izquierda' (categorías que, vale la pena mencionar, son incapaces por completo de describir la realidad de lo político hoy día, pero que siguen siendo utilizadas por el ancien régime como si tuvieran algún referente real). En palabras de Villalobos-Ruminott 'el hecho de que la derecha neoliberal sea profundamente populista y de que su populismo esté habilitado mediáticamente, implica que ya no es posible sostener, ingenuamente, que las actuales disputas políticas en América Latina se dan entre un sector populista y anti neoliberal y otro republicano y liberal, sino entre, al menos, dos versiones distintas del populismo' (2018, 49).
} 
adecuadas a ellas [...] El populismo es competitivo en el campo de la comunicación política, pero él no ha creado la regla de un juego superficial y poco argumentativo (2015: 44-45).

Villacañas logra sintetizar el problema de la razón y la pasión según la entienden los detractores del populismo. Primero y muy importante, el populismo no inventa nuevas reglas. No es que el modelo liberal hubiera creado cada vez más ciudadanos clásicos, y el populismo irrumpiera para incitar el analfabetismo político; simplemente encontró una manera más eficiente de comunicar un mensaje a las masas. Parte fundamental de ello es el logro de que más personas elaboraran una relación entre su experiencia propia y un discurso (el populista).

Es como si el populismo hubiera tomado una página de la Lógica de Port-Royal para demostrar que la forma más eficaz de hacer política en la época de Twitter y Facebook era soltar la batuta en la producción de evidencia para sustentar la veracidad del mensaje, y dejar que cada quien la produzca por sí y para sí mismo. El populismo se dio cuenta de que, en tiempos de masas y medios masivos de comunicación, producir un mensaje coherente y consistente con la creencias de todos los receptores no sólo era una tarea sumamente compleja, sino poco eficiente. La lección que Cherniak le ofreció al populismo fue que resultaba mejor ofrecer estructuras discursivas ambiguas, que apelaran a la manera en que el sujeto estaba construyendo su mundo, lo cual sólo podía darse en el marco de una lógica portroyaliana, esto es, en el entendido de que la validación de cada argumento no recae el otro, sino en sí mismo.

Repito, esto no significa que el discurso populista sea irracional, simplemente está sustentado en otra idea de racionalidad. La crítica al populismo que afirma que la apelación al afecto, al sentimiento y a la teatralidad es un ataque a la Razón, vive en un paradigma que ya no tiene que ver con la realidad de las sociedades occidentales. Dicho argumento descansa sobre el axioma de que la razón ilustrada es la única 
razón, y cualquier discurso que contravenga sus axiomas o premisas es, necesariamente, irracional. ${ }^{21}$ En el fondo, lo que el sistema liberal sabe es que la puesta en movimiento del dispositivo populista es incompatible con sus propios fundamentos; sospecha - consciente o inconscientementeque está jugando un juego que no puede ganar y por eso no tiene otro remedio más que gritar: ¡trampa!

Lo que realmente acecha a la estructura liberal es que el discurso populista no es un recurso facilón que apela a los sentimientos, sino uno coherente, que invoca otro tipo de racionalidad que simplemente no es la suya. El juicio hecho a partir de un sentimiento o un afecto sigue siendo un juicio racional, sigue teniendo una estructura racional mínima, sólo que no es ni esa racionalidad ideal que fundó el proyecto liberal, ni el pragmatismo que lo sostuvo por décadas. ${ }^{22}$ El gran peligro del populismo es que ha puesto en entredicho la vieja dicotomía moderna entre ciudadanos y salvajes, entre la razón y la pasión. Ha introducido una manera diferente de entender la distribución de lo racional y lo sensible, y ésta pone en peligro toda la lógica de dominio que, durante siglos, mantuvo a una pequeña élite — caracterizada por su uso y conocimiento de las reglas de la razón ilustrada- en el poder.

21 Aquí habría que ser justos con el texto de Villacañas. Creo que él entiende esto perfectamente, pero no puede abundar en ello dada la naturaleza divulgadora de su texto y a cuestiones de extensión. Podemos encontrar evidencia de esto desde la introducción, cuando hace una referencia velada a la naturaleza ilustrada de lo que normalmente se considera la razón: 'El populismo impugna que la base de la sociedad sea racional. Su reto es cómo vivir una vez que las sospechas acerca de la dialéctica de la razón ilustrada se han tornado ya sentencias firmes y ejecutadas' (2015: 16). La referencia a la dialéctica (de la ilustración) y la naturaleza instrumental de la razón ilustrada son un guiño más.

22 A primera vista, el discurso populista sería muy similar al pragmatismo del siglo XX, sin embargo, a nivel axiomático son radicalmente distintos. Esta distinción se relaciona con el referente mismo de la certeza que hasta aquí hemos discutido. Si bien, desde el pragmatismo de William James se busca, al igual que en Port-Royal, que nuestro pensamiento sobre el mundo alcance una claridad perfecta, el carácter verificacionista del pragmatismo refiere al exterior, esto es: el referente de la claridad está en el objeto exterior y no en la idea interior. Cualquier mecanismo de comprobación sobre dicha claridad transitaría por la figura del otro o por una estructura con pretensiones de objetividad, como la lógica. Así, lo que Peirce llama un 'grado superior de claridad' remite a un acuerdo o un consenso sobre la opinión de la cosa; por su lado, Dewey sostuvo que el referente de la verdad se encuentra en la experimentación y la probabilística, mientras que Rorty busca que, por lo menos, las bases sobre las cuales se desplanta cualquier investigación del mundo sean objetivas. En resumen, el pragmatismo niega cualquier teoría sobre la verdad que sea correspondista, mientras que la similitud entre Port-Royal y el discurso populista se da en la medida en que sustentan la verdad en una correspondencia entre el mundo y el yo. 


\section{VI.}

...a veces estamos convencidos de la corrección de un punto de vista por su simplicidad o su simetría, es decir, son éstas las que nos inducen a adoptar el punto de vista en cuestión. En tal caso, nos limitamos a decir: 'Así debe ser'. Ludwig Wittgenstein

Ahora, sigue habiendo una pregunta no atendida, una particularidad del discurso populista que todavía no hemos tocado: ¿qué tiene que ver todo lo dicho hasta aquí con ese antiinstitucionalismo preponderante no sólo en la estructura populista, sino en el seno mismo de las sociedades occidentales?

En La sociedad del cansancio, Byung-Chun Han (2017) echa mano de filósofos como Arendt, Agamben y Foucault, y sus reflexiones históricopolíticas, para describir dos tipos de sociedades que sirven como casos para construir una analogía. El primero corresponde a un tiempo en donde los modelos para describir los fenómenos sociales siguen una lógica biológica, según la cual los riesgos y los peligros que acaecen a la sociedad tienen la misma forma que las enfermedades bacteriales: en ellas, el enemigo cobra la forma de un agente exterior a la sociedad, como un virus o una bacteria. Su diferencia radical es constitutiva, y es dicha diferencia lo que me amenaza: el enemigo es identificable por sus rasgos (raza, color, género). Esta diferencia crea visibilidades que me dan certeza; éstas reafirman la homogeneidad de la comunidad de amigos, en la medida en que pueden producir un enemigo común para todos. Es una época de instituciones. Son ellas las garantes de la validez de esta diferencia. Pareciera que hoy en día esta metáfora se encuentra rebasada en lo que refiere a la explicación de los 'riesgos' que acechan a las sociedades occidentales. En una época de masas, el paradigma biológico es muy poco eficiente. La creación de una homogeneidad en la que todos compartimos un enemigo es tarea en extremo difícil para cualquier institución: la sociedad de masas, por 
naturaleza, se beneficia de la producción de diferencias, aún más en regímenes democráticos con sistemas de producción capitalistas.

El segundo tipo de sociedad que describe Han corresponde a aquella organizada de acuerdo a un modelo en donde la lógica ya no es biológica, sino psíquica, por lo que la naturaleza de las enfermedades ya no sigue una forma bacterial, sino neuronal. Este paradigma parece asemejarse más a nuestras sociedades neoliberales, en condición posmoderna. Dado el descrédito que padecen continuamente las instituciones, la producción homogénea de un enemigo se torna cada vez más compleja; lo cual, aunado a la necesidad sistemática de eficiencia incremental, resulta en un desplazamiento del locus de la producción del enemigo, de la institución hacia el individuo: el yo produce la otredad que explica aquello que le asedia. El enemigo se vuelve, entonces, un modelo (Deleuze, 2015). Puede ser el inmigrante, el extranjero, el fundamentalista o cualquier otro tipo de no-yo. La producción pasa de ser positiva a pura negatividad. ${ }^{23}$

La ambigüedad del discurso populista se convierte en una ventaja competitiva dado que, en una época como la nuestra, la estrategia más efectiva no es producir un enemigo que actúe como fuerza políticamente vinculante, sino dar creencia a todas las posibles creencias individuales; esto es: trasladar el garante de la verdad de la institución al yo. El discurso populista le dice a cada individuo: lo que tú crees que es responsable de tus males o los de tu comunidad, eso es. Legitima al yo: le asegura que está en lo correcto.

No es casualidad que Han (2015) note que el modelo actual, el neuronal, no tenga su origen en la ciencia, como sí lo hacía el biológico. En tanto ciencia, la biología requiere verificar sus propuestas. Si bien no escapa del escándalo de la inducción, sigue una secuencia de reglas que exige a los postulados gozar de una repetibilidad verificable, cercana a la perfección, 
para ostentarse como verdades. Mientras tanto, si nos aventuramos a considerar la psicología como ciencia nos ubicamos más dentro de las reglas de las ciencias sociales (Hempel, 2005), que demandan simplemente cierta eficiencia estadística para postular enunciados verdaderos.

La complejidad del sistema científico biológico forma su propia institucionalidad: en dicho modelo la verdad es sumamente difícil de producir y comunicar. La institución existe como garante cuando una verdad es utilizada: está ahí para dar certeza a la sociedad. Este modelo, como ya se mencionó, no es el más eficiente para el ejercicio de la política en una época de masas. Esto no quiere decir que no sea 'correcto', simplemente no puede competir ante el populista, más parecido al paradigma neuronal y apegado a una lógica como la de Port-Royal, en la cual el garante de la verdad del mundo es el individuo mismo.

Villacañas está en lo correcto cuando afirma que, históricamente, el populismo no surge de las masas, sino que éstas son el término al cual se dirige. La raíz del populismo no son las masas, sino el antielitismo $(2015,41)$. Debemos reconciliarnos con el hecho de que el orden liberal - por lo menos la manera en que se manifestó en los últimos siglos- es elitista. Es difícil encontrar una democracia moderna que no haya sido una oligocracia o una aristocracia velada; de nuevo, Adorno y Horkheimer ya lo habían advertido recién terminada la Segunda Guerra Mundial. Ni hablar del neoliberalismo, cuyo programa es, en-sí, la restauración de una jerarquía liberal que históricamente se había desdibujado para apaciguar las demandas sociales de principios del siglo XX (Harvey, 2015).

El discurso populista contemporáneo logra comunicar este antielitismo de una forma muy particular y por demás eficiente. Entiende que las sociedades actuales ya no se organizan alrededor de bloques o partes productoras de identidad, ${ }^{24}$ sino que la producción de (su) identidad

24 'El populismo se debe considerar como un fenómeno plural, complejo, cambiante, tendencial gradual, que tiene en cuenta la multiplicidad social, con su producción permanente de diferencias. El populismo, en términos 
recae por completo sobre el individuo. El populismo no intenta generar un 'nosotros los antielitistas': simplemente produce un 'ellos los elitistas' a partir de un ejercicio de pura negación; esto es, el discurso populista sólo se (re)presenta a sí mismo como todo lo que no es.

Bastaría fijarnos en las estrategias retóricas más eficaces del partido republicano, en especial las aprendidas del Tea Party, para hallar un claro ejemplo de cómo funciona este discurso. Cerca de las elecciones intermedias de 2010, la táctica adelantada por el partido republicano fue simple: el candidato debía identificarse como lo que no era, comenzando un mitin o una presentación expresando algo como: "escuchen, yo no tengo un título de una universidad Ivy League, pero sí sé que...'. El fin de este tipo de mensaje era unir a los oyentes a partir de lo que no eran, después de eso, la producción de identidad recaía en cada uno de ellos. ${ }^{25}$ Cada quien puede creer lo que quiera y producirse a sí mismo a partir de dichas creencias, el que éstas resulten contradictorias entre los múltiples individuos que forman la comunidad no importa, porque el vínculo comunitario es negativo: podemos ser diferentes entre nosotros, pero en lo que coincidimos todos es en que no somos ellos: las élites. Podemos tener creencias diferentes incluso contradictorias-, pero tenemos algo en común, que no creemos en lo que creen ellos: en las instituciones. 


\section{VII.}

El no pagarle a tiempo a un trabajador no sólo es un delito, se viola la Constitución. Es un pecado, está en la Biblia, en el Antiguo Testamento, y hasta se los puedo citar. Andrés Manuel López Obrador

Pensemos en el fenómeno de la migración, algo que ocupa una parte primordial en la gran mayoría de los discursos populistas contemporáneos, si no es que en todos. Han (2015) afirma que la figura del inmigrante se establece de forma distinta, a la par del cambio de paradigma que propone. El inmigrante no sería, como en el modelo biológico, el otro inmunológico que entra a mi cuerpo a destruirlo; en el paradigma actual, el inmigrante deja de ser considerado una amenaza externa y se entiende más bien como una carga sobre la cual la sociedad - aunque lo reconoce con un grado de igualdad- dice no tener los recursos suficientes para sobrellevarlo. El análisis de Han es sumamente interesante, y creo que acierta en muchas de las cosas que parecen estar sucediendo en la actualidad; por lo menos, sus descripciones parecen dar cuenta del rumbo que toma el mundo. Sólo veo dos problemas: el primero, que sigue siendo una interpretación y una propuesta fundamentalmente liberal. El segundo, que al discurso populista no le importa qué tan acertada sea su descripción, porque la perspectiva liberal opera desde los prejuicios de la razón ilustrada, y el discurso populista sabe que ahí no está la eficiencia.

El discurso populista elabora una estructura discursiva dentro de la cual caben ambos paradigmas sobre el migrante, y cualquier otro que genere una comunidad. El gran éxito del discurso populista radica en que funciona aun si existiera alguna contradicción 'ontológica' supuesta (esto es, si en efecto existiera lo que el inmigrante realmente es). La funcionalidad del discurso populista permite que un hombre en sus setentas identifique al 
inmigrante como siempre lo ha hecho: un intruso que viene a destruirlo a él y a todo lo que él cree que lo representa; también permite a un hombre blanco, urbano, conservador pensar al mismo inmigrante como un ser humano, con derechos, que simplemente es una carga que a él o a su país no le toca llevar; a la vez, permite a un mexicano-estadounidense ver a un hondureño como un migrante, igual que él, pero que no cumple con la ley, a diferencia suya.

Hay un cierto éxito político y una eficiencia retórica innegable en un discurso que permite cierta ambigüedad ontológica; que aleja el locus de la certeza sobre lo que la cosa es de la creencia en una posible interpretación objetiva, y lo acerca más a lo que cada individuo cree que es. No hay mayor eficiencia que elaborar un discurso en el cual cabe cualquier representación del mundo, porque lo que le da validez es que se sustente sólo en la idea que cada quien tiene sobre lo que es el mundo, y en la creencia de que no hay nadie, mucho menos ninguna institución, que tenga legitimidad para decirme que eso que yo creo, no es así.

\section{VIII.}

A lo largo de mi vida, mis más grandes activos han sido mi estabilidad mental y ser, tipo, muy inteligente [...] Pase de ser un hombre de negocios MUY exitoso a ser una estrella de televisión y luego presidente de los Estados Unidos (a la primera). Creo que eso me hace no inteligente, sino un genio... iу un genio muy estable ya que estamos en eso!

Donald Trump

Siento necesario reiterar que mi intención con estas líneas no ha sido, de ninguna manera, hacer una apología del discurso populista. He querido dejar en claro que seguir haciendo crítica del populismo desde un marco liberal, desde los axiomas y los presupuestos de la razón ilustrada, es 
continuar ignorando el hecho de que, justamente las limitaciones patentes de dichos sistemas y de las democracias modernas producto de éstos, fueron los fundamentos que permitieron el ascenso y el éxito del discurso populista. ${ }^{26}$ Asumir la petición de principio de que la razón ilustrada está siendo atacada por las pasiones de las masas enardecidas, y que, ante todo, debemos defenderla, simplemente abonará a la exacerbación y el anquilosamiento de esa élite, que no fue capaz de atender las demandas de una era democratizante. Quizá habría que entender el discurso y los movimientos populistas como los siguientes pasos, lógicos y eficientes, en lo que Villalobos-Ruminott (2013) ha llamado filosofía de la historia del capital y, a partir de ahí, problematizar el papel que la representación ha jugado en dicha historia.

El proyecto entero de Port-Royal, que no sólo comprende su Lógica sino también su Gramática, tiene como fin 'actuar correctamente sobre las cosas por medio del juicio que nos hacemos de éstas, es decir, su representación’ (Marin: 2006, 361). Si la historia de la representación en la modernidad occidental es la de las formas de evidenciar un desplazamiento ontológico y las maneras en que éste se valida, esto es, las maneras en que se puede garantizar que lo que se representa es lo que es, entonces podría resumirse su pendiente histórica de la siguiente manera: con Port-Royal se inaugura la representación como vía para hacer presente lo que está ausente —el poder de la institución monárquico-eclesiástica absoluta-, la institución recibirá un golpe traumático a partir de la segunda mitad del siglo $\mathrm{XX}$, cuando la representación se comience a entender a partir de los fundamentos del a priori histórico (Mendiola, 2006).

Esta modalidad, que desconfía de la institución moderna, sigue teniendo a la noción de cultura, en tanto una totalidad, como su garante onto-histórico de validez, lo cual significa, hasta cierto grado, un límite a 
la escala y a los alcances de la lógica de creación y acumulación de capital. El entendimiento populista de la ideología neoliberal, por un lado, y de los medios masivos de comunicación de segundo orden (Twitter, Instagram, Facebook), por el otro, devuelve la validez de la representación al yo. Es decir, la operación de representación vuelve a ser, como en la Lógica de Port-Royal, introspectiva, ${ }^{27}$ pero el garante de la verdad ontológica de la representación ya no reside en la seguridad institucional de que una divinidad ha instalado en mí los mecanismos para representar 'lo que realmente es', sino que el individuo ahora posee esos poderes antes reservados para la divinidad. La fe individual del sujeto neoliberal en que las cosas son como él las representó, porque así las representó, es en sí el mecanismo de validación más eficiente para el discurso populista. Los likes en Twitter, Facebook e Instagram no son, como lo notan la mayoría de los críticos, mecanismos de validación para las representaciones - $\mathrm{O}$ los discursos-; son más bien mecanismos de reafirmación y creación de vínculos comunitarios. La validez la da 'el yo', y la comunidad de amigos se crea a partir de la retro-reafirmación de los distintos 'yo', sin que haya ninguna institución o set de reglas que verifiquen la coherencia o consistencia entre la multiplicidad de representaciones y discursos que constituyen dicha comunidad de amigos. Si entendemos esta lógica como una parte en el proceso de incremento de eficiencia en la historia de la filosofía del capital, significaría no sólo mirar nuestros fenómenos contemporáneos desde un marco completamente distinto, sino que llamaría también a re-narrar, desde dicho marco, toda la historia del siglo XX.

\footnotetext{
27 Recordemos que el garante de que la cosa representada en mi juicio concuerda con lo que la cosa 'realmente es' es la idea —natural e innata. De ahí que Marin note: 'Yo me represento la cosa por medio de la idea, tales son los tres polos de la noción de representación en su efectuación: yo como res cogitans o sujeto de representación, el proceso de representación, relación "especular" con la cosa, la idea en la cual la cosa está presente al pensamiento. El juicio, nos dicen los gramáticos y lógicos, es una forma o una manera de pensar que, como tal, no lleva a otra cosa que a un yo de afirmación pura que no comporta ningún proceso de representación' (2006: 365-366.)
} 
¿Qué implicaría esto? Primero que nada, entender que la crisis contemporánea no se trata de la Razón contra la Pasión, sino de maneras de entender y reelaborar lo que significa razonar y sentir, y redibujar los límites - si es que los hay- entre ellos. Buscar entre las aporías y las contradicciones para encontrar ese tercio excluido. Ya existe quien lo intenta, como los llamados a la construcción de una democracia salvaje y una anarquía de los sentidos por parte de Villalobos-Ruminott (2018), o el de Alberto Moreiras (2018) a pensar en la posibilidad de un populismo marrano y la infrapolítica como forma de vida.

La pregunta restante tendría que ver con este regreso al solipsismo que parece mandar hoy día y que he tratado de mostrar aquí. Cuando Moreiras piensa en las posibilidades de un populismo sin arche, y VillalobosRuminott alienta nuestra curiosidad, invitándonos a pensar una distribución anárquica de la sensibilidad, sin duda abren una discusión que va más allá de la mera oposición entre el ancien régime ilustrado y un discurso populista irracional y pasional. No debemos dejar de problematizar el hecho de que el éxito brutal y aplastante, a nivel global, del neoliberalismo ha logrado trasladar ese arche, en tanto principio y mandato, a la figura del yo. Esto es: en un regreso al solipsismo, el neoliberalismo ha encontrado una ideología eficiente y redituable. En esta configuración discursiva, es muy fácil construir la ilusión de la ausencia total del arche.

Habría que preguntarnos si, en efecto, las cosas son así. En retrospectiva, la Lógica de Port-Royal utilizó las nociones de espíritu y de lo innato y natural de las ideas para colocar el punto de validación sobre la certeza del mundo en el yo, de cómo son, en verdad, las cosas. El punto ciego de la estructura tautológica de Port Royal es que, por todos lados aparece - a veces explícitamente, a veces implícitamente- la institución que parecería se trata de ocultar o de hacer superflua. El proyecto ilustrado venció al de Port-Royal porque, en su base, lo que quería era sacar al hombre del solipsismo, en un tiempo en que fe y solipsismo eran inseparables. Hoy 
en día, recurrir a los presupuestos ilustrados para hacer frente al populismo no sólo es anacrónico, también inútil: el discurso populista ha encontrado en una vuelta al solipsismo una herramienta vital para el campo de batalla socio-político. Quedaría preguntar si queremos, o si es necesario, formular una cosa pública que haga frente al discurso populista, y de ser así, cómo construirla, a contrapelo con la fuerte corriente actual de una forma del solipsismo que ha mostrado tener un gran valor para la política, el capital y todo lo que resulte de una amalgama entre los tres. 


\section{Referencias}

Adorno, T.W. y Horkheimer, M. (1994). Dialéctica de la Ilustración.Madrid: Trotta. Arnauld, A. y Nicole, P. (1987). La Lógica o el arte de pensar. Madrid: Alfaguara.

Barrios, J.L. (2018). Los Pinos: poéticas y patéticas del poder simbólico. Nexos (versión digital)

Borges, J.L. (1998) Otras inquisiciones. Madrid: Alianza

Blumenberg, H. (2011). Descripción del ser humano. México: FCE.

Brinkman-Clark, W. (2015) La crisis de la crítica. El monopolio cultural y la agonía de la operación crítica en las democracias modernas. Historia y grafía 44, 47-88.

Cherniak, C. (1986). Minimal Rationality. Cambridge: MIT Press.

Descartes, R. (1995). Meditaciones metafísicas. Quito: Libresa.

Deleuze, G. (2015). Curso sobre Foucault. Vol 1. El saber. Buenos Aires: Cactus.

Ferrajoli, L. (1999) Derechos y garantías. La ley del más débil. Madrid: Editorial Trotta.

Foucault, M. (2010). Las palabras y las cosas. México: Siglo XXI.

Han, B.C. (2015). La expulsión de lo distinto. Barcelona: Herder.

Han, B.C. (2017). La sociedad del cansancio. Barcelona: Herder.

Harvey, D. (2015). Breve historia del neoliberalismo. Madrid: Akal.

Hempel, C.G. (2005). La explicación científica: estudios sobre la filosofía de la ciencia. Barcelona: Paidós.

Horkheimer, M. (2007). Crítica de la razón instrumental. La Plata: Terramar.

Kant, I. (2014) Antropología en el sentido pragmático (edición bilingüe alemánespañol). México: FCE/UAM/UNAM.

Kuhn, T. (2004). La estructura de las revoluciones científicas. México: FCE.

Marin, L. (2006). La crítica del discurso. Sobre la 'Lógica de Port-Royal' y los 'Pensamientos' de Pascal. En: V. Torres Septien (coord.), Producciones de sentido, 2. Algunos conceptos de la historia cultural (págs. 357-387). México: Universidad Iberoamericana. 
Mendiola, A. (2006) Las representaciones como temas de estudio en la historia. Una aproximación desde Louis Marin. En: V. Torres Septien (coord.), Producciones de sentido, 2. Algunos conceptos de la historia cultural (págs. 343-355). México: Universidad Iberoamericana.

Moreiras, A. (2018). Plomo hegemónico. Consideraciones sobre la hipótesis Podemos. En: A. Loureiro y R. Price (eds.), ¿El populismo por venir? (págs. 87-118). Madrid: Escolar y Mayo Editores.

Pinker, S. (2018). Los populistas están en el lado oscuro de la historia. El País (versión digital) https://elpais.com/elpais/2018/06/07/eps/1528366679_426068.html

Villalobos-Ruminott, S. (2013). Soberanías en suspenso. Imaginación y violencia en América Latina. Lanus: La Cebra.

Villalobos-Ruminott, S. (2018) Acerca de la posibilidad de una democracia salvaje. Pensamiento al margen. Núm. Especial Infrapolítica y democracia, 33-63. 